\title{
Association between CSF alpha-synuclein seeding activity and genetic status in Parkinson's disease and dementia with Lewy bodies
}

\author{
Kathrin Brockmann ${ }^{1,2^{*}}$, Corinne Quadalti ${ }^{3}$, Stefanie Lerche ${ }^{1,2}$, Marcello Rossi ${ }^{3}$, Isabel Wurster ${ }^{1,2}$, \\ Simone Baiardi ${ }^{3,4}$, Benjamin Roeben ${ }^{1,2}$, Angela Mammana ${ }^{3}$, Milan Zimmermann ${ }^{1,2}$, Ann-Kathrin Hauser ${ }^{1,2}$, \\ Christian Deuschle ${ }^{1,2}$, Claudia Schulte ${ }^{1,2}$, Katharina Waniek ${ }^{5}$, Ingolf Lachmann ${ }^{5}$, Simon Sjödin ${ }^{6}$, \\ Ann Brinkmalm ${ }^{6,7}$, Kaj Blennow ${ }^{6,7}$, Henrik Zetterberg ${ }^{6,7,8,9}$, Thomas Gasser ${ }^{1,2}$ and Piero Parchi ${ }^{3,4^{*}}$ (i)
}

\begin{abstract}
The clinicopathological heterogeneity in Lewy-body diseases (LBD) highlights the need for pathology-driven biomarkers in-vivo. Misfolded alpha-synuclein (a-Syn) is a lead candidate based on its crucial role in disease pathophysiology. Real-time quaking-induced conversion (RT-QuIC) analysis of CSF has recently shown high sensitivity and specificity for the detection of misfolded a-Syn in patients with Parkinson's disease (PD) and dementia with Lewy bodies (DLB). In this study we performed the CSF RT-QulC assay in 236 PD and 49 DLB patients enriched for different genetic forms with mutations in GBA, parkin, PINK1, DJ1, and LRRK2. A subgroup of 100 PD patients was also analysed longitudinally. We correlated kinetic seeding parameters of RT-QuIC with genetic status and CSF protein levels of molecular pathways linked to a-Syn proteostasis. Overall, 85\% of PD and 86\% of DLB patients showed positive RT-QulC a-Syn seeding activity. Seeding profiles were significantly associated with mutation status across the spectrum of genetic LBD. In PD patients, we detected positive a-Syn seeding in 93\% of patients carrying severe GBA mutations, in 78\% with LRRK2 mutations, in 59\% carrying heterozygous mutations in recessive genes, and in none of those with bi-allelic mutations in recessive genes. Among PD patients, those with severe GBA mutations showed the highest seeding activity based on RT-QulC kinetic parameters and the highest proportion of samples with 4 out of 4 positive replicates. In DLB patients, 100\% with GBA mutations showed positive a-Syn seeding compared to $79 \%$ of wildtype DLB. Moreover, we found an association between a-Syn seeding activity and reduced CSF levels of proteins linked to a-Syn proteostasis, specifically lysosome-associated membrane glycoprotein 2 and neurosecretory protein VGF.
\end{abstract}

\footnotetext{
*Correspondence: kathrin.brockmann@uni-tuebingen.de; piero. parchi@unibo.it

${ }^{1}$ Department of Neurodegeneration, Center of Neurology, Hertie Institute for Clinical Brain Research, German Center for Neurodegenerative Diseases, University of Tuebingen, Hoppe Seyler-Strasse 3, 72076 Tuebingen, Germany

${ }^{3}$ IRCCS Istituto delle Scienze Neurologiche di Bologna, Via Altura 1/8, 40139 Bologna, Italy

Full list of author information is available at the end of the article
} permits use, sharing, adaptation, distribution and reproduction in any medium or format, as long as you give appropriate credit to the original author(s) and the source, provide a link to the Creative Commons licence, and indicate if changes were made. The images or other third party material in this article are included in the article's Creative Commons licence, unless indicated otherwise in a credit line to the material. If material is not included in the article's Creative Commons licence and your intended use is not permitted by statutory regulation or exceeds the permitted use, you will need to obtain permission directly from the copyright holder. To view a copy of this licence, visit http://creativecommons.org/licenses/by/4.0/. The Creative Commons Public Domain Dedication waiver (http://creativeco mmons.org/publicdomain/zero/1.0/) applies to the data made available in this article, unless otherwise stated in a credit line to the data. 
These findings highlight the value of a-Syn seeding activity as an in-vivo marker of Lewy-body pathology and support its use for patient stratification in clinical trials targeting a-Syn.

Keywords: a-Syn seeding, RT-QulC, CSF, PD, GBA, Parkin

\section{Introduction}

The current gold-standard diagnosis for Parkinson's disease (PD) is based on clinicopathological criteria that include neuronal loss in the substantia nigra pars compacta and Lewy-body (LB) pathology related to alpha-synuclein $(\alpha-$ Syn) aggregation [1-3]. However, histopathological findings in some genetic forms of PD challenge this definition. While PD patients with mutations in the $G B A$ gene $\left(\mathrm{PD}_{\mathrm{GBA}}\right)$ show extensive $\mathrm{LB}$ pathology, most PD patients with bi-allelic mutations in the recessive gene parkin $\left(\mathrm{PD}_{\text {recessive bi-allelic }}\right)$ show nigral degeneration without LBs [4]. The histopathology in PD patients with LRRK2 mutations ( $\left.\mathrm{PD}_{\mathrm{LRRK} 2}\right)$ is also remarkably variable, including typical LB pathology, misfolded tau deposition or nigral degeneration without LBs [5-7]. This heterogeneity highlights the need for pathology-driven biomarkers that distinguish between the different underlying pathologies in-vivo. With disease-modifying treatment options targeting $\alpha$-Syn underway, patient stratification according to $\alpha$-Syn-specific enrichment strategies is a much-needed prerequisite to introduce patients to clinical trials.

As we have no reliable imaging marker to assess the cerebral load of $\alpha$-Syn in-vivo, research has focused on CSF. Yet, it is unclear whether CSF profiles of $\alpha$-Syn species reflect $\alpha$-Syn brain pathology. Analyses in sporadic $\mathrm{PD}$ and $\mathrm{PD}_{\mathrm{GBA}}$ demonstrated decreased CSF levels of total $\alpha$-Syn compared to controls with the highest decrease in $\mathrm{PD}_{\mathrm{GBA}}$ patients carrying severe mutations [8-10]. However, a substantial inter-individual variability and overlap with controls are seen so that CSF levels of total $\alpha$-Syn are not ideal as a single biomarker. Recently, the ultrasensitive assays real-time quaking-induced conversion (RT-QuIC) and protein misfolding cyclic amplification have been successfully implemented. These assays exploit the seeding capacities of prion or prion-like proteins as an amplification strategy to reveal minute amounts of disease-specific protein aggregates in CSF $[11,12]$. Both methods showed a high sensitivity of $88-96 \%$ and $83-98 \%$ specificity for sporadic LBD such as PD and DLB compared to controls $[13,14]$. However, only one study on a limited number of patients has applied the $\alpha$-Syn RTQuIC assay to patients with genetic PD [15].

\section{Materials and methods}

\section{Aim, design and setting of the study}

To further asses the value of $\alpha$-Syn RT-QuIC, as pathology-driven biomarker for LBD, we assessed CSF $\alpha$-Syn seeding activity in two large cohorts with LBD enriched for genetic forms. We included PD and DLB patients with $G B A$ mutations as a proxy for pronounced $\alpha$-Syn pathology, and PD patients with parkin, PINK1 and DJ1 mutations as representatives for nigral degeneration with sparse or no $\alpha$-Syn aggregation. Moreover, PD patients with $L R R K 2$ mutations were assessed. As no study has yet analyzed $\alpha$-Syn seeding capacities longitudinally, we also evaluated $\alpha$-Syn seeding profiles throughout the disease course in repeatedly collected CSF samples.

Besides, as several molecular pathways associated with $\alpha$-Syn proteostasis have been identified over the last decade [16], we evaluated associations between $\alpha$-Syn seeding profiles and CSF levels of proteins representative of these pathways.

\section{Participants}

Between 2005 and 2020, 236 PD patients, 49 DLB patients, 14 asymptomatic mutation carriers, and 26 healthy controls have been recruited at the University Hospital of Tuebingen. Specifically, CSF of 108 sporadic PD patients $\left(\mathrm{PD}_{\text {wildtype }}\right), 99 \mathrm{PD}$ patients with GBA mutation $\left(\mathrm{PD}_{\mathrm{GBA}}\right), 9 \mathrm{PD}$ patients with LRRK2 mutation $\left(\mathrm{PD}_{\mathrm{LRRK}}\right), 20 \mathrm{PD}$ patients with mutations in parkin, PINK1, or DJ1 (17 $\mathrm{PD}_{\text {recessive heterozygous }} 3$ $\mathrm{PD}_{\text {recessive_bi-allelic }}$ ), 33 DLB patients without $G B A$ mutation $\left(\mathrm{DLB}_{\text {sporadic }}\right)$ and 16 DLB patients with $G B A$ mutation $\left(\mathrm{DLB}_{\mathrm{GBA}}\right)$ was available. See Additional file 1: Table S1 for the complete list of mutations.

Repeated lumbar punctures allowing longitudinal CSF measurements were performed in $100 \mathrm{PD}$ patients (61 $\mathrm{PD}_{\text {wildtype }}, 34 \mathrm{PD}_{\mathrm{GBA}}, 2 \mathrm{PD}_{\mathrm{LRRK} 2}, 3 \mathrm{PD}_{\text {recessive _heterozygous }}$ ). See Additional file 2: Figure S1.

\section{Genetic analysis}

Genetic screening for mutations in GBA, LRRK2, parkin, PINK1 and DJ1 was done as previously described [17]. 


\section{Clinical investigations}

All participants were examined by a movement disorders specialist. Diagnosis of PD was defined according to UK Brain Bank Society Criteria [18]. Diagnosis of DLB was made according to the DLB consortium revised consensus criteria; only patients with probable DLB were included [19]. Patients were assessed in dopaminergic ON. We assessed severity of motor symptoms using part III of the Unified Parkinson's disease Rating Scale (UPDRS-III), from 2006-2008 the old version, from 2009 on the MDS-UPDRS [20]. Disease stage was categorized by modified Hoehn and Yahr Scale (H\&Y) [21]. Cognitive function was tested with Montreal Cognitive Assessment (MoCA) [22] and/or Mini Mental Status Examination (MMSE) [23]. Since the MoCA was available only from 2009 on, previously obtained MMSE scores were converted into MoCA equivalents [24].

\section{CSF collection}

Spinal tap was performed between 9.00 am and $1.00 \mathrm{pm}$. Samples were centrifuged within $60 \mathrm{~min}$ and frozen at $-80{ }^{\circ} \mathrm{C}$ within $90 \mathrm{~min}$ after collection. Samples with abnormal routine CSF diagnostics (erythrocytes $>1 / \mu \mathrm{l}$, white blood cell count $>5$ cells $/ \mu$, immunoglobulin subtype $\mathrm{G}$ index $>0.7$ ) were excluded.

\section{Alpha-synuclein real-time quaking-induced conversion assay (RT-QulC)}

We performed purification of recombinant wildtype human $\alpha$-Syn and the various steps of the RT-QuIC assay as described [14]. In addition to the negative control, we ran the same positive sample throughout all experiments to optimize the comparison between fluorescent responses in different plates. To overcome batch-to-batch variations and intrinsic plate-to-plate variability, we normalized the relative fluorescent units (RFU) for every time point to the maximum intensity reached by the positive control within each plate and expressed it as percentage. Intra-assay and inter-assays CVs before and after normalization are reported in Additional file 3: Table S2.

We calculated the threshold as the average normalized fluorescence value of negative control repeats during the first $10 \mathrm{~h}$ of recording, plus 30 standard deviations. The cut-off was set at $30 \mathrm{~h}$. When only one of the four replicates crossed the threshold, the analysis was considered "unclear" and repeated up to three times. In those participants who showed a positive RT-QuIC $\alpha$-Syn seeding profile (at least 2 out of 4 runs), we measured the area under the curve (AUC), the peak of the fluorescence response (Imax), and the lag phase (LAG) (time required to reach the threshold).

RT-QuIC experiments were performed at the Institute of Neurological Science of Bologna (ISNB). Results were reported blinded of the clinical diagnosis and genetic status. The assay showed a high specificity (98.7\%) for LB pathology in a series of 121 CSF samples from individuals referred to the laboratory of neuropathology at ISNB for dementia of various etiologies in which the presence of LBs and abnormal $\alpha$-Syn deposits was excluded by neuropathological examination [25].

\section{CSF measurement of total alpha-synuclein}

CSF levels of total $\alpha$-Syn were assessed using an ELISA kit for human $\alpha$-Syn (Roboscreen GmbH, Germany). Intraassay imprecision of $4.4 \%$ was calculated from duplicate analyses and expressed as median of the range to average of the duplicates. Inter-assay imprecision of $<10 \%$ was determined using two quality control CSF pool samples.

\section{CSF measurements of proteins related to alpha-synuclein proteostasis}

Measurements of the following protein concentrations were performed using parallel reaction monitoring mass spectrometry (PRM-MS) as previously described [26, 27].

1. Neurotransmitter secretion: chromogranin-A (CHGA), secretogranin-2 (SCG2), neurosecretory protein VGF (VGF).

2. Synapse plasticity: neuronal pentraxin-1 (NPTX1).

3. Autophagy, including endocytosis, lysosomal function, and ubiquitin-proteasome system: AP-2 complex subunit beta (AP2B1), cathepsin F (CTSF), ganglioside GM2 activator (GM2A), lysosome-associated membrane glycoprotein 2 (LAMP2), ubiquitin.

\section{Sample preparation}

$50 \mu \mathrm{L}$ CSF was mixed with $50 \mu \mathrm{L}$ of an internal standard mixture containing stable isotope-labelled peptides (JPT Peptide Technologies GmbH, Berlin, Germany; Thermo Fisher Scientific Inc. Waltham, MA, USA), 13C-labelled ubiquitin (Silantes, GmbH, Munich, Germany) and bovine serum albumin (Sigma-Aldrich Co., Saint Louis, MO, USA), diluted in $50 \mathrm{mM} \mathrm{NH4HCO3.} \mathrm{Reduction} \mathrm{and}$ alkylation was performed by addition of $50 \mu \mathrm{L} 15 \mathrm{mM}$ 1,4-dithiothreitol in $50 \mathrm{mM} \mathrm{NH} 4 \mathrm{HCO} 3$, shaking for $30 \mathrm{~min}$ at $60^{\circ} \mathrm{C}$, cooling down at room temperature for $30 \mathrm{~min}$, and addition of $25 \mu \mathrm{L} 70 \mathrm{mM}$ iodoacetamide in $50 \mathrm{mM}$ NH4HCO3 followed by shaking at room temperature in the dark for $30 \mathrm{~min}$. Samples were digested by the addition of $25 \mu \mathrm{L} 0.08 \mu \mathrm{g} / \mu \mathrm{L}$ sequencing grade modified trypsin (Promega Co., Madison, WI, USA) diluted in $50 \mathrm{mM} \mathrm{NH} 4 \mathrm{HCO} 3$ and incubated at $37{ }^{\circ} \mathrm{C}$ shaking for $18 \mathrm{~h}$. Digestion was ended by addition of $25 \mu \mathrm{L} 10 \%$ trifluoroacetic acid. Solid-phase extraction was performed 
using Oasis ${ }^{\circledR}$ HLB 96-well $\mu$ Elution Plates (2 mg sorbent and $30 \mu \mathrm{m}$ particle size; Waters Co., Milford, MA, USA) by conditioning $(2 \times 300 \mu \mathrm{L}$ methanol), equilibration $(2 \times 300 \mu \mathrm{L} \mathrm{H} 2 \mathrm{O})$, loading of samples, washing $(2 \times 300 \mu \mathrm{L}$ $\mathrm{H} 2 \mathrm{O})$, and elution $(2 \times 100 \mu \mathrm{L}$ methanol). Samples were dried by vacuum centrifugation and stored at $-80^{\circ} \mathrm{C}$.

\section{Parallel reaction monitoring mass spectrometry (PRM-MS)}

Samples were dissolved by addition of $50 \mu \mathrm{L} 50 \mathrm{mM}$ $\mathrm{NH} 4 \mathrm{HCO} 3$ and shaken at room temperature for $1 \mathrm{~h}$. Forty $\mu \mathrm{L}$ of sample were injected and separated using a Dionex $^{\mathrm{TM}}$ UltiMate $^{\mathrm{TM}} 3000$ standard-LC system (Thermo Fisher Scientific Inc., Waltham, MA, USA) and a Kinetex ${ }^{\circledR}$ EVO C18 column (length $150 \mathrm{~mm}$; inner diameter $2.1 \mathrm{~mm}$; particle size $1.7 \mu \mathrm{m}$; Phenomenex Inc., Torrance, CA, USA) with a SecurityGuard ${ }^{\mathrm{TM}}$ ULTRA cartridge prefilter (Phenomenex Inc.). On a 60 min method, with solvents A $(0.1 \%$ formic acid in $\mathrm{H} 2 \mathrm{O}(\mathrm{v} / \mathrm{v}))$ and B $(84 \%$ acetonitrile and $0.1 \%$ formic acid in $\mathrm{H} 2 \mathrm{O}(\mathrm{v} / \mathrm{v})$ ), using a flow rate of $300 \mu \mathrm{L} / \mathrm{min}$, the gradient went from 3 to $5 \%$ B over one minute followed by $5-26 \%$ B over $48 \mathrm{~min}$. The column temperature was set to $50{ }^{\circ} \mathrm{C}$. Separation by high-performance liquid chromatography was performed in online mode coupled to a Q Exactive ${ }^{\mathrm{TM}}$ Hybrid Quadrupole-Orbitrap $^{\mathrm{TM}}$ mass spectrometer (Thermo Fisher Scientific Inc.). Using a HESI-II ionization probe (Thermo Fisher Scientific Inc.) electrospray ionization was performed in positive ion mode with the following settings: spray voltage $+4.1 \mathrm{kV}$, heater temperature $400{ }^{\circ} \mathrm{C}$, capillary transfer tube temperature $380^{\circ} \mathrm{C}$, sheath gas flow rate 25 , auxiliary gas flow rate 10 , and S-Lens RF level 60. Acquisition of data was performed using single microscan in PRM mode with an isolation window of $\mathrm{m} / \mathrm{z} 2$ centred on the second isotope of the precursor ion. The resolution setting was $70 \mathrm{k}$ with an AGC target of $1 \times 106$ and a $256 \mathrm{~ms}$ injection time. Fragmentation was performed using higher energy collision-induced dissociation.

\section{Data extraction}

Skyline v.19.1 was used to calculate and export fragment ion peak areas and to monitor fragment ion traces and ratios. The ratio between tryptic peptide and isotopelabelled peptide peak area was used for quantification.

\section{CSF measurement of $A \beta_{1-42}$, total-Tau (t-Tau), phospho-Tau} (p-Tau), neurofilament light protein (NFL)

CSF levels of $A \beta_{1-42}, t$-Tau and $p$-Tau were measured using ELISA kits from INNOTEST, Fujirebio $\mathrm{GmbH}$, Germany. CSF levels of NFL were measured using the UmanDiagnostics NF-light ${ }^{\circledR}$ assay. Intra-assay coefficients of variation for each CSF parameter were below $15 \%$.

\section{Statistical analysis}

Statistical analysis was performed using IBM SPSS 26.0 software. Group comparisons of dichotomous data were analyzed using the likelihood-ratio chi-square test as it is suited for unequally distributed samples sizes. Intergroup comparisons (disease groups stratified by genetic mutation; $\alpha$-Syn seeders vs. non-seeders) of demographics, clinical markers, and CSF parameters were calculated using ANOVA/ANCOVA including sex, age, age at onset, and disease duration as co-variates as appropriate. Pearson's correlation was used to evaluate associations between RT-QuIC seeding profiles and clinical markers and CSF parameters. Longitudinal analysis of RT-QuIC $\alpha$-Syn seeding was done using linear mixed model with fixed factors group (seeders vs. non-seeders) and time (time of follow-up in years), their interaction and the random variable subject, modelled by random intercepts. Hypothesis testing was 2 -sided and $p$ values $\leq 0.05$ were considered statistically significant.

\section{Results}

Demographic and clinical characteristics of all groups and subgroups are given in Table 1 and 2 and Additional file 4: Table S3, Additional file 5: Table S4, and Additional file 6: Tables S5.

\section{RT-QuIC seeding activity is associated with disease status and genetic mutations \\ Association with disease}

Eighty-five percent of PD and $86 \%$ of DLB patients showed a positive RT-QuIC $\alpha$-Syn seeding activity compared to $8 \%$ of controls (Table 1 ). Of the asymptomatic mutation carriers, $14 \%$ (1 GBA, 1 LRRK2) were $\alpha$-Syn seeding positive. A single PD patient showing 1 out of 4 positive replicates by RT-QuIC in three runs was excluded from analyses given the inconclusive result.

There were no significant differences in RT-QuIC seeding kinetics (AUC, Imax, and LAG) between PD and DLB patients with positive $\alpha$-Syn seeding $(p>0.05)$.

Male sex and higher age were associated with positive $\alpha$-Syn seeding (sex: $\mathrm{r}=0.139, p=0.019)$ and higher numbers of positive RT-QuIC replicates (sex: $\mathrm{r}=-0.133$, $p=0.024$; age: $\mathrm{r}=0.127, p=0.033$ ).

\section{Association with genetic mutations}

While $91 \%$ of $\mathrm{PD}_{\text {wildtype }}$ and $87 \%$ of $\mathrm{PD}_{\mathrm{GBA}}$ (93\% of $\mathrm{PD}_{\mathrm{GBA}_{\text {_severe }}}$ ) showed positive $\alpha$-Syn seeding activity, $78 \%$ of $\mathrm{PD}_{\mathrm{LRRK} 2}$ and only $59 \%$ of $\mathrm{PD}_{\text {recessive heterozygous gave a }}$ positive reaction. None of the $\mathrm{PD}_{\text {recessive_bi-allelic }}$ showed positive $\alpha$-Syn seeding (overall $p \leq 0.001$ ) (Fig. 1A, B). 
Table 1 RT-QulC seeding profiles stratified by diagnosis

\begin{tabular}{|c|c|c|c|c|c|c|}
\hline & $\begin{array}{l}P D \\
n=235\end{array}$ & $\begin{array}{l}\text { DLB } \\
n=49\end{array}$ & $\begin{array}{l}p \text { Value PD/DLB } \\
\text { vs. controls }\end{array}$ & $\begin{array}{l}\text { Controls } \\
n=26\end{array}$ & $\begin{array}{l}\text { Asymptomatic } \\
\text { mutation carriers } \\
n=14\end{array}$ & $\begin{array}{l}p \text { Value } \\
\text { asymptomatic } \\
\text { mutation carriers } \\
\text { vs. Controls }\end{array}$ \\
\hline Male Sex \% & 65 & 70 & 0.237 & 54 & 36 & 0.271 \\
\hline Age (y) & $64 \pm 9$ & $72 \pm 7^{* * *}$ & $\leq 0.001$ & $59 \pm 12$ & $58 \pm 15$ & 0.855 \\
\hline Age at onset (y) & $57 \pm 10$ & $68 \pm 7^{* * *}$ & - & - & - & - \\
\hline Disease duration (y) & $7 \pm 6$ & $3 \pm 2^{* * *}$ & - & - & - & - \\
\hline UPDRS III & $25 \pm 11$ & $30 \pm 13^{*}$ & $\leq 0.001$ & $2 \pm 2$ & $1 \pm 1$ & 0.112 \\
\hline MoCA & $25 \pm 4$ & $15 \pm 6^{* * *}$ & $\leq 0.001$ & $27 \pm 3$ & $28 \pm 2$ & 0.303 \\
\hline LEDD & $544 \pm 475$ & $392 \pm 216^{*}$ & - & - & - & \\
\hline RT-QulC positive seeding n (\%) & $200(85)$ & $42(86)$ & $\leq 0.001$ & $2(8)$ & $2(14)$ & 0.516 \\
\hline RT-QulC 0/4 positive seeding n (\%) & $35(15)$ & $7(14)$ & $\leq 0.001$ & $18(92)$ & $12(86)$ & 0.363 \\
\hline RT-QulC 2/4 positive seeding n (\%) & $18(8)$ & $1(2)$ & & $1(4)$ & 0 & \\
\hline RT-QulC 3/4 positive seeding n (\%) & $54(23)$ & $12(25)$ & & 0 & $1(7)$ & \\
\hline RT-QulC 4/4 positive seeding n (\%) & $128(54)$ & $29(59)$ & & $1(4)$ & $1(7)$ & \\
\hline RT-QuIC AUC & $761 \pm 239$ & $804 \pm 225$ & - & - & - & - \\
\hline RT-QulC Imax & $70 \pm 13$ & $69 \pm 12$ & - & - & - & - \\
\hline RT-QuIC LAG & $21 \pm 3$ & $20 \pm 3$ & - & - & - & - \\
\hline CSF total alpha-synuclein pg/ml & $567 \pm 262$ & $535 \pm 322^{*}$ & 0.175 & $583 \pm 181$ & $627 \pm 389$ & 0.677 \\
\hline $\mathrm{CSF} A \beta_{1-42} \mathrm{pg} / \mathrm{ml}$ & $713 \pm 262$ & $518 \pm 229^{* *}$ & $\leq 0.001$ & $925 \pm 231$ & $885 \pm 407$ & 0.693 \\
\hline CSF t-Tau pg/ml & $242 \pm 132$ & $328 \pm 238$ & 0.151 & $240 \pm 97$ & $242 \pm 120$ & 0.955 \\
\hline CSF p-Tau pg/ml & $41 \pm 16$ & $49 \pm 28$ & 0.429 & $41 \pm 13$ & $44 \pm 17$ & 0.561 \\
\hline NFL pg/ml & $917 \pm 850$ & $1921 \pm 1888^{* * *}$ & $\leq 0.001$ & $542 \pm 239$ & $431 \pm 91$ & 0.294 \\
\hline
\end{tabular}

MoCA montreal cognitive assessment, UPDRS III Unified Parkinson Disease Rating Scale part III, LEDD L-Dopa equivalent daily dose

$p$ values were corrected for age and sex when compared to controls and age, age at onset and disease duration for comparison of PD vs. DLB where appropriate. Significance level PD vs. DLB: ${ }^{*} p<0.05,{ }^{* *} p<0.01,{ }^{* * *} p \leq 0.001$

In PD patients with positive $\alpha$-Syn seeding, AUC was highest in $\mathrm{PD}_{\text {GBA_severe }}$ (median $858 \mathrm{RFU}$ ) and lowest in $\mathrm{PD}_{\text {recessive_heterozygous }}$ (median $702 \mathrm{RFU}$; overall $p=0.048$ ). Accordingly, $\mathrm{PD}_{\mathrm{GBA} \_ \text {severe }}$ had the shortest LAG phase $(19 \mathrm{~h}$; overall $p=0.009)$ (Table 2$)$.

$\mathrm{PD}_{\text {GBA_severe }}$ showed also the highest proportion of samples with 4 out 4 positive replicates among PD groups (overall $p \leq 0.001$ ).

In DLB, $100 \%$ of $\mathrm{DLB}_{\mathrm{GBA}}$ showed positive $\alpha$-Syn seeding activity compared to $79 \%$ of $\operatorname{DLB}_{\text {wildtype }}(p=0.014)$ (Fig. 1A).

AUC, Imax, and LAG in DLB patients with positive $\alpha$-Syn seeding were comparable between wildtype and GBA status ( $p>0.05$, respectively) (Additional file 4: Table S3).

\section{RT-QuIC seeding activity is associated with lower CSF protein levels related to alpha-synuclein-proteostasis} Positive $\alpha$-Syn seeding and higher numbers of positive replicates were associated with lower CSF levels of LAMP2 $(\mathrm{r}=-0.178, p=0.012 ; \mathrm{r}=-0.146, p=0.040)$ and VGF $(\mathrm{r}=-0.187, p=0.008 ; \mathrm{r}=-0.160, p=0.023)$.
Higher RT-QuIC AUC and shorter LAG were associated with lower CSF levels of AP2B1 $(r=-0.224$, $p=0.003 ; \quad \mathrm{r}=0.215, \quad p=0.004), \quad$ CHGA $\quad(\mathrm{r}=-0.176$, $p=0.018 ; \quad \mathrm{r}=0.168, \quad p=0.024), \quad$ CTSF $\quad(\mathrm{r}=-0.176$, $p=0.018 ; \quad \mathrm{r}=0.161, \quad p=0.030), \quad$ SCG2 $\quad(\mathrm{r}=-0.185$, $p=0.012 ; \mathrm{r}=0.159, p=0.033)$, ubiquitin $(\mathrm{r}=-0.219$, $p=0.004 ; \mathrm{r}=0.239, p=0.002)$, and VGF $(\mathrm{r}=-0.204$, $p=0.006 ; \quad \mathrm{r}=0.184, \quad p=0.013$ ) (Additional file 5 : Table S4).

Correspondingly, $\alpha$-Syn seeders showed lower mean CSF levels of LAMP2 (PD: 1.00) and VGF (PD: 0.93; DLB: 0.57) compared to non-seeders (PD: LAMP2 1.27, $p=0.05$, VGF 1.36, $p=0.014$; DLB: VGF 0.90, $p=0.05$ ) (Additional file 6: Table S5).

Higher age and female sex were associated with higher CSF levels of AP2B1, CHGA, GM2A, LAMP2, SCG2, ubiquitin, and VGF $(p<0.01$, respectively). No associations were found with disease duration.

\section{RT-QuIC seeding activity is associated with motor and cognitive impairment}

Positive $\alpha$-Syn seeding and higher numbers of positive RT-QuIC replicates were associated with higher 
Table 2 RT-QulC seeding profiles in PD stratified by mutation status

\begin{tabular}{|c|c|c|c|c|c|c|c|c|}
\hline & $\begin{array}{l}P_{\text {wildtype }} \\
n=107\end{array}$ & $\begin{array}{l}\mathrm{PD}_{\mathrm{GBA} \text { risk }} \\
\mathrm{n}=53\end{array}$ & $\begin{array}{l}\mathrm{PD}_{\mathrm{GBA} \text { mild }} \\
\mathrm{n}=17\end{array}$ & $\begin{array}{l}\mathrm{PD}_{\mathrm{GBA} \_ \text {severe }} \\
\mathrm{n}=\mathbf{2 9}\end{array}$ & $\begin{array}{l}\text { PD } \\
n=9\end{array}$ & $\begin{array}{l}P_{\text {recessive_heterozygous }} \\
\mathrm{n}=17\end{array}$ & $\begin{array}{l}\mathrm{PD}_{\text {recessive_bi-allelic }} \\
\mathrm{n}=3\end{array}$ & $p$ value \\
\hline Male sex $\%$ & 70 & 70 & 65 & 66 & 33 & 41 & 33 & 0.096 \\
\hline Age (y) & $65 \pm 8$ & $65 \pm 9$ & $66 \pm 9$ & $59 \pm 10$ & $65 \pm 13$ & $62 \pm 13$ & $63 \pm 9$ & 0.070 \\
\hline Age at onset (y) & $61 \pm 8$ & $58 \pm 10$ & $57 \pm 9$ & $51 \pm 10$ & $53 \pm 14$ & $51 \pm 13$ & $36 \pm 6$ & $\leq 0.001$ \\
\hline Disease Duration (y) & $5 \pm 3$ & $8 \pm 5$ & $8 \pm 6$ & $9 \pm 7$ & $12 \pm 7$ & $11 \pm 10$ & $27 \pm 2$ & $\leq 0.001$ \\
\hline UPDRS III & $23 \pm 10$ & $28 \pm 11$ & $28 \pm 13$ & $27 \pm 13$ & $27 \pm 9$ & $27 \pm 11$ & $22 \pm 1$ & 0.265 \\
\hline MoCA & $26 \pm 3$ & $24 \pm 5$ & $25 \pm 6$ & $24 \pm 5$ & $24 \pm 4$ & $26 \pm 3$ & $27 \pm 5$ & 0.005 \\
\hline LEDD & $389 \pm 259$ & $595 \pm 363$ & $626 \pm 252$ & $701 \pm 545$ & $802 \pm 399$ & $830 \pm 1241$ & $1497 \pm 1481$ & \\
\hline RT-QulC positive (\%) & $97(91)$ & $48(91)$ & $11(65)$ & $27(93)$ & $7(78)$ & $10(59)$ & $0(0)$ & $\leq 0.001$ \\
\hline RT-QulC 0/4 positive (\%) & $10(9)$ & $5(9)$ & $6(35)$ & $2(7)$ & $2(22)$ & $7(41)$ & $3(100)$ & $\leq 0.001$ \\
\hline RT-QulC 2/4 positive (\%) & $13(12)$ & $1(2)$ & $1(6)$ & $0(0)$ & $0(0)$ & $3(18)$ & $0(0)$ & \\
\hline RT-QulC 3/4 positive (\%) & $29(27)$ & $11(21)$ & $3(18)$ & $5(17)$ & $3(33)$ & $3(18)$ & $0(0)$ & \\
\hline RT-QulC 4/4 positive (\%) & $55(52)$ & $36(68)$ & $7(41)$ & $22(76)$ & $4(45)$ & $4(23)$ & $0(0)$ & \\
\hline RT-QulC AUC & $713 \pm 238$ & $795 \pm 281$ & $797 \pm 157$ & $858 \pm 179$ & $843 \pm 191$ & $702 \pm 202$ & n.a & 0.048 \\
\hline RT-QuIC Imax & $68 \pm 14$ & $71 \pm 15$ & $72 \pm 12$ & $71 \pm 10$ & $75 \pm 7$ & $67 \pm 12$ & n.a & 0.378 \\
\hline RT-QuIC LAG & $21 \pm 3$ & $20 \pm 3$ & $20 \pm 2$ & $19 \pm 2$ & $19 \pm 3$ & $21 \pm 2$ & n.a & 0.009 \\
\hline $\begin{array}{l}\text { CSF total } \\
\mathrm{a}-S y n \mathrm{pg} / \mathrm{ml}\end{array}$ & $578 \pm 279$ & $560 \pm 212$ & $489 \pm 220$ & $512 \pm 273$ & $712 \pm 319$ & $567 \pm 221$ & $840 \pm 487$ & 0.171 \\
\hline $\mathrm{CSF} A \beta_{1-42} \mathrm{pg} / \mathrm{ml}$ & $679 \pm 249$ & $684 \pm 268$ & $706 \pm 214$ & $779 \pm 248$ & $972 \pm 302$ & $753 \pm 299$ & $854 \pm 262$ & 0.208 \\
\hline CSF t-Tau pg/ml & $232 \pm 127$ & $265 \pm 152$ & $241 \pm 100$ & $203 \pm 86$ & $334 \pm 190$ & $261 \pm 144$ & $179 \pm 19$ & 0.191 \\
\hline CSF p-Tau pg/ml & $41 \pm 16$ & $39 \pm 12$ & $43 \pm 15$ & $36 \pm 16$ & $54 \pm 21$ & $45 \pm 20$ & $42 \pm 6$ & 0.227 \\
\hline $\mathrm{NFL} \mathrm{pg/ml}$ & $894 \pm 633$ & $1042 \pm 1320$ & $1099 \pm 965$ & $839 \pm 635$ & $832 \pm 311$ & $720 \pm 419$ & $571 \pm 87$ & 0.816 \\
\hline
\end{tabular}

MoCA Montreal cognitive assessment, UPDRS III Unified Parkinson Disease Rating Scale part III, n.a. not applicable, LEDD L-Dopa equivalent daily dose $p$ values were corrected for age, age at onset and disease duration
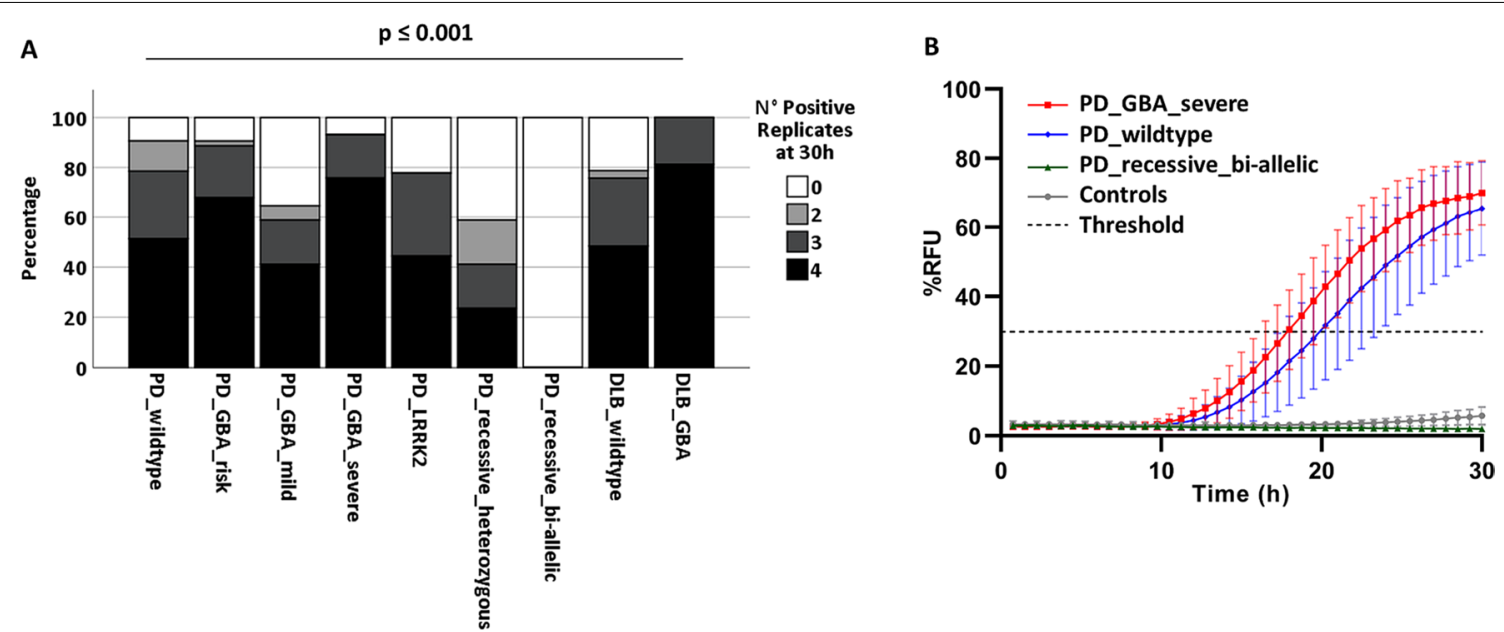

Fig. 1 RT-QulC positive replicates relative fluorescence curves at $30 \mathrm{~h}$ stratified by diagnosis and mutation status. A Remarkable differences in RT-QulC a-Syn seeding profiles were detected in the PD patients' group when stratifying by PD-associated mutations. While $93 \%$ of $P D_{G B A}$ severe showed a positive RT-QulC a-Syn seeding profile, $78 \%$ of $\mathrm{PD}_{\mathrm{LRRK} 2}$ and only $59 \%$ of $\mathrm{PD}_{\text {recessive_heterozygous }}$ gave a positive reaction by RT-QuIC. Strikingly, none of the $P D_{\text {recessive_bi-allelic }}$ showed a positive RT-QulC a-Syn seeding profile (overall $p \leq 0.001$ ) Numbers $(n)$ included: $P D_{\text {wildtype }}=107$, $\mathrm{PD}_{\mathrm{GBA} \text { _risk }}=53, \mathrm{PD}_{\mathrm{GBA} \text { mild }}=17, \mathrm{PD}_{\mathrm{GBA} \text { _severe }}=29, \mathrm{PD}_{\mathrm{LRRK} K 2}=9, \mathrm{PD}_{\text {recessive_heterozygous }}=17, \mathrm{PD}_{\text {recessive_biallelic }}=3, \mathrm{DLB}_{\text {wildtype }}=33, \mathrm{DLB} \mathrm{B}_{\mathrm{GBA}}=16$. $\mathbf{B}$ While $\mathrm{PD}_{\mathrm{GBA} \text { severe }}$ patients showed the strongest RT-QulC seeding kinetics measured by the mean relative fluorescence (RFU) of positive curves (see comparison with $\mathrm{PD}_{\text {wildtype }}$ ), $\mathrm{PD}_{\text {recessive_bi-allelic }}$ did not seed at all. 
UPDRS-III $(\mathrm{r}=0.148, p=0.024 ; \mathrm{r}=0.189, p=0.004)$ and lower MoCA scores $(\mathrm{r}=-0.163, p=0.016 ; \mathrm{r}=-0.256$, $p \leq 0.001)$.

Higher RT-QuIC AUC and shorter LAG were associated with higher UPDRS-III $(\mathrm{r}=0.150, p=0.034$; $\mathrm{r}=-0.165, \quad p=0.020)$ and lower MoCA scores $(\mathrm{r}=-0.189, p=0.009 ; \mathrm{r}=0.186, p=0.011)$ (Additional file 5: Table S4). There were no associations with disease duration.

RT-QulC alpha-synuclein seeders compared to non-seeders Despite a shorter disease duration (7 years), PD patients with positive $\alpha$-Syn seeding activity had a higher UPDRSIII (26) and lower MoCA score (25) compared to nonseeders $(9$ years disease duration, UPDRS-III $21, \mathrm{MoCA}$ 27; $p<0.01$ respectively).

DLB patients with positive $\alpha$-Syn seeding activity had a higher prevalence of REM-sleep behaviour disorder (RBD) ( $50 \%$ vs. $0 \%, p=0.049)$ whereas sex, age, age at onset, disease duration, prevalence of parkinsonism and the interval between onset of parkinsonism and onset of dementia were not statistically significant when compared to non-seeders. DLB RT-QuIC non-seeders had higher mean CSF levels of t-Tau (533 vs. 294; $p=0.012$ ) and NFL (3586 vs. $1630 ; p=0.010$ ) compared to RTQuIC seeders (Additional file 6: Table S5).

\section{RT-QuIC seeding profiles remain stable over time}

Out of 100 PD patients included in this longitudinal analysis, 86 were RT-QuIC seeding positive. Mean time between first and last lumbar puncture was 3.5 years in RT-QuIC seeding positive and 3.4 years in RT-QuIC seeding negative patients. Linear mixed model analyses revealed that the number of positive RT-QuIC replicates did not change over time, neither in the overall longitudinal PD cohort ( $p=0.670$ ) (Fig. 2A) nor in those PD patients with first LP at disease duration $<2$ years $(p=0.949)$. Similarly, $\alpha-S y n$ seeding positives showed stable results of AUC $(p=0.576), \operatorname{Imax}(p=0.558)$ and LAG phase $(p=0.324)$ over time (Fig. 2B, C).

\section{Discussion}

The present results show a significant association between RT-QuIC $\alpha$-Syn seeding activity and mutation status across the LBD spectrum. Remarkably, mutations in $G B A$, especially those classified as severe, showed the highest percentage of positive $\alpha$-Syn seeding activity in both PD (93\%) and DLB (100\%). In contrast, PD patients with bi-allelic mutations in recessively inherited genes like parkin or PINK1 did not show CSF $\alpha$-Syn seeding at all, whereas those carrying heterozygous mutations in these genes showed less $\alpha$-Syn seeding than wild-type cases with a reduced positivity rate of $59 \%$. Also, PD

\section{Longitudinal RT-QuIC measurements in 100 PD Patients}
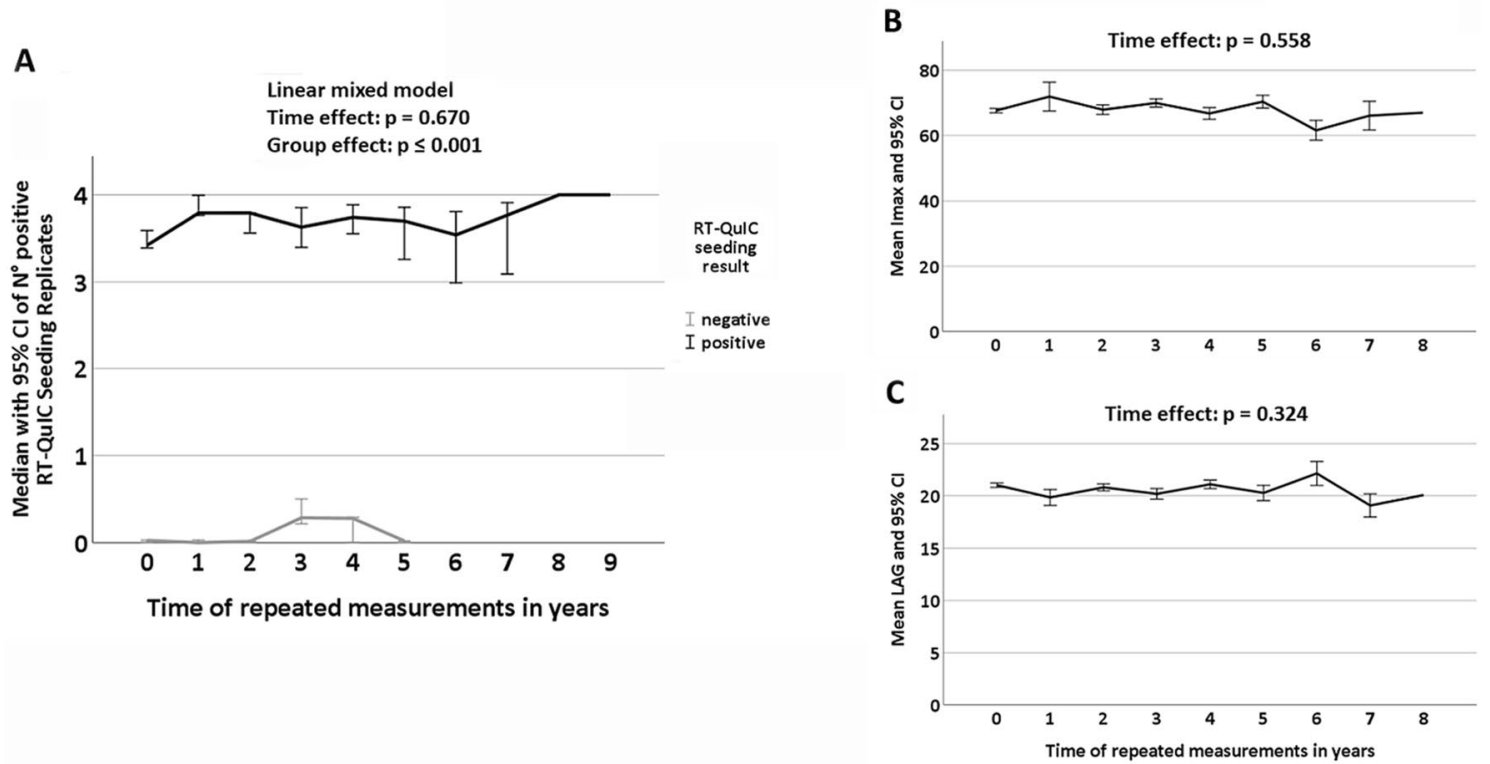

Fig. 2 Longitudinal trajectories of RT-QulC seeding profiles. Out of the 100 PD patients included in this longitudinal analysis, 86 were RT-QulC seeding positive while 14 did not show seeding. A Linear mixed model analysis in the longitudinal PD cohort with repeated lumbar puncture and RT-QulC assay measurements revealed that time had no significant impact on the number of positive RT-QulC seeding replicates over the course of the disease, neither in those patients who were seeding positive nor in those who were seeding negative $(p=0.670)$. B, C Similarly, RT-QulC seeding positives showed stable results of Imax $(p=0.558)$ and LAG phase $(p=0.324)$ over time 
patients with $L R R K 2$ mutations showed a reduced rate of $\alpha$-Syn seeding (78\%), although not to the extent previously reported in a Spanish cohort carrying the p.G2019S mutation [15]. The broader spectrum of mutations in our cohort, along with differences in clinical features such as older age and longer disease duration, might have contributed to these different results. Larger cohorts of patients carrying other mutations are needed to comprehensively evaluate the effect of $L R R K 2$ on $\alpha$-Syn pathology.

Overall, $85 \%$ of PD and $86 \%$ of probable DLB patients showed $\alpha$-Syn seeding activity, which is slightly lower than the percentage obtained in previous studies [11-13]. The characteristics of our cohort, enriched for different genetic mutations, including those not harbouring LB pathology, best explain the results in PD patients. In contrast, the relatively low number of patients combined with the purely clinical diagnosis (akinetic-rigid parkinsonism, dementia and hallucinations in all cases) without supportive biomarkers (MIBG, DaTScan) possibly explain the lower frequency of positive cases in our wildtype DLB cohort. Moreover, previously analyzed DLB cohorts might have included some patients carrying a mutation in $G B A$ given that they were not characterized genetically. Interestingly, patients with DLB that were RT-QuIC seeding negative had fewer clinical core features related to $\alpha-S y n$ pathology such as RBD [28]. These results suggest that most of the negative $\alpha$-Syn RT-QuIC outcomes we obtained in patients with a clinical diagnosis of DLB did not indicate false-negative assay results. Indeed, it is well known from post-mortem and CSF studies that heterogeneous pathologies may sustain this clinical syndrome [19]. Consistent with this interpretation is the finding that DLB patients carrying GBA mutations, who were all positive by $\alpha$-Syn RT-QuIC, showed normal mean CSF profile of $\mathrm{t}$-Tau, $\mathrm{p}$-Tau and $\mathrm{A} \beta_{1-42}$, whereas the group of sporadic DLB patients without $G B A$ mutations presented higher mean CSF levels of t-Tau, p-Tau and $\mathrm{NfL}$ as well as reduced $A \beta_{1-42}$ levels indicating a typical Alzheimer's disease profile. The heterogeneity in $\alpha$-Syn seeding activity among the different genetic forms of PD mirrors histopathological findings in these cases. While PD patients with GBA mutations show extensive $\alpha$-Synpositive LB pathology, those with bi-allelic mutations in parkin or PINK1 show nigral degeneration without LB, whereas those carrying LRRK2 mutations show LB pathology in most cases, but also misfolded tau deposition or nigral degeneration without LB pathology $[4,29]$.

Additionally, we demonstrated an association between RT-QuIC parameters expressing higher $\alpha$-Syn seeding activity (higher AUC, shorter LAG) with lower CSF levels of proteins related to $\alpha$-Syn proteostasis, including autophagy, endocytosis, lysosomal function, ubiquitin-proteasome system and neurosecretion. Accordingly, PD and DLB patients with positive RTQuIC seeding showed reduced CSF levels of lysosomalassociated membrane glycoprotein 2 and neurosecretory protein VGF compared to patients with negative seeding. Recent studies reported lower CSF protein levels of AP2-complex subunit beta, cathepsin F, ganglioside GM2 activator, lysosomal-associated membrane glycoprotein 1 and 2, and ubiquitin in PD compared to patients with Alzheimer's disease and controls, and decreased CSF levels of chromogranin-A and $\mathrm{B}$, neurosecretory protein VGF, and secretogranin species in PD and DLB compared to controls [30,31]. Interestingly, lower CSF levels of VGF were associated with lower CSF levels of $\alpha$-Syn while no association was found with $A \beta_{1-42}[32,33]$. These data suggest that amplification assays such as RTQuIC might provide new tools to study in-vivo the mechanistic link between proteins linked to $\alpha$-Syn proteostasis and seeding, which was previously shown only in postmortem studies and cell models [34-39].

Besides the capacity to accurately discriminate patients with LB pathology in-vivo, it will be essential to determine whether $\alpha$-Syn RT-QuIC may have a role in predicting clinical trajectories. Increased $\alpha$-Syn seeding capacities might predispose to accelerated/widespread $\alpha$-Syn aggregation, thereby promoting faster progression to clinical disease milestones such as cognitive impairment. Our finding of an association between RT-QuIC kinetics parameters (AUC, LAG) with more severe motor impairment and cognitive dysfunction suggests that this might be the case. However, additional studies in prospective longitudinal cohorts where CSF and clinical data are available in de-novo PD patients with several years of follow-up, combined with further refinement of the quantitative capabilities of the assay are needed to fully address the value of the $\alpha$-Syn RT-QuIC as a prognostic marker in LBD patients.

Most asymptomatic mutation carriers did not show RT-QuIC $\alpha$-Syn seeding. The two RT-QuIC $\alpha$-Syn positive mutation carriers (1GBA, 1 LRRK2) were older and had lower MoCA scores than the negative ones. The observation is in line with a recent study in LRRK2 mutation carriers where only $19 \%$ showed a positive seeding compared to $20 \%$ of the control group. Those with positive seeding activity had higher likelihood ratios for probable prodromal PD [15]. These findings warrant further longitudinal investigations of larger cohorts with mutation carriers enriched for prodromal symptoms specific for $\alpha$-Syn such as RBD.

Repeated longitudinal measurements revealed stable RT-QuIC $\alpha$-Syn seeding profiles. This finding implicates that seeding activity represents a trait marker for $\alpha$-Syn pathology rather than a marker that simply increases 
with time or disease duration. Further analysis in longitudinal cohorts with de-novo patients is needed to evaluate $\alpha$-Syn seeding activity in different disease stages prospectively. The full reproducibility of the $\alpha$-Syn RT-QuIC positive vs. negative outcome in samples taken from the same patients longitudinally also supports the assay's value as a specific pathology-driven biomarker of $\alpha$-Syn pathology.

Strengths of our study include the large monocentric standardized collection of CSF samples minimizing variance in sample collection and processing, the validation of findings in longitudinal samples from the same patients, and the reproducibility in two alpha-synucleinopathies.

Limitations are the lack of longitudinal correlation between CSF RT-QuIC $\alpha$-Syn seeding activity and postmortem brain histopathology and the small/imbalanced sample sizes of genetic subgroups and those stratified by RT-QuIC seeding profiles.

\section{Conclusions}

Our finding of heterogeneous seeding profiles across genetic forms of LBD suggest that CSF RT-QuIC $\alpha$-Syn seeding activity is highly representative of and mirrors LB brain pathology in-vivo. We also show that RT-QuIC $\alpha$-Syn seeding activity is associated with reduced CSF levels of proteins related to $\alpha$-Syn proteostasis supporting mechanistic links suggested by in-vitro models. Importantly, this assay allows patient stratification according to $\alpha$-Syn-specific enrichment strategies in preparation for clinical trials targeting $\alpha$-Syn.

\footnotetext{
Abbreviations

ISNB: Institute of Neurological Science of Bologna; LP: Lumbar puncture; LBD: Lewy body disease; LB: Lewy body; CSF: Cerebrospinal fluid; a-Syn: Alphasynuclein; RT-QulC: Real-time quaking-induced conversion; PD: Parkinson's disease; DLB: Dementia with Lewy bodies; $\mathrm{PD}_{\mathrm{GBA}}$ : $\mathrm{PD}$ patients with mutations in the GBA gene, further classified as $P_{\mathrm{GBA}_{\text {_risk, }}} \mathrm{PD}_{\mathrm{GBA} \text { mild }}$ or $\mathrm{PD}_{\mathrm{GBA} \text { s severe }}$ based on the specific mutation/s occurring in the GBA gene; $P D_{\text {recessive_bi-allelic: }} P D$ patients with bi-allelic mutations in the recessive genes parkin, PINK1 or DJ1; $P D_{\text {recessive_heterozygous: }}$ PD patients with mutations in parkin, PINK1, or DJ1; $\mathrm{PD}_{\mathrm{LRRK} 2}: \mathrm{PD}$ patients with $\angle R R K 2$ mutations; $\mathrm{PD}_{\text {wildtype: }}$ Patients with sporadic

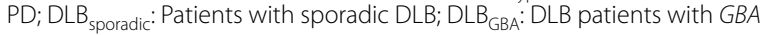
mutations; MoCA: Montreal cognitive assessment; MMSE: Mini mental status examination; AUC: Area under the curve; Imax: Maximum of intensity (related to RT-QuIC); LAG: The lag phase (time required to reach the threshold); PRMMS: Parallel reaction monitoring mass spectrometry; CHGA: Chromogranin-A; SCG2: Secretogranin-2; VGF: Neurosecretory protein VGF; NPTX1: Neuronal pentraxin-1; AP2B1: AP-2 complex subunit beta; CTSF: Cathepsin F; GM2A: Ganglioside GM2 activator; LAMP2: Lysosome-associated membrane glycoprotein 2; $A \beta_{1-42}$ : Beta-amyloid protein, fragment 1-42; t-Tau: Total Tau; p-Tau: Tau phosphorylated at position 181; NFL: Neurofilament light chain; MIBG: Nuclear medicine imaging test using metaiodobenzylguanidine; DaTScan: Dopamine active transfer scan.
}

\section{Supplementary Information}

The online version contains supplementary material available at https://doi. org/10.1186/s40478-021-01276-6.
Additional file 1: Table S1. Genetic mutations stratified by gene in PD and DLB. The table shows the prevalence of genetic mutations observed in each group of the analysed cohort.

Additional file 2: Figure S1. Schematic representation of study design. Between 2005 and 2020, 236 PD patients, 49 DLB patients, 14 asymptomatic mutation carriers, and 26 healthy controls have been recruited at the University Hospital of Tuebingen. Specifically, CSF of 108 sporadic PD patients ( $\left(\mathrm{PD}_{\text {wildtype }}\right), 99 \mathrm{PD}$ patients with $\mathrm{GBA}$ mutation $\left(\mathrm{PD} \mathrm{GBA}_{\mathrm{GA}}\right), 9 \mathrm{PD}$ patients with $L R R K 2$ mutation $\left(\mathrm{PD}_{\mathrm{LRRK} 2}\right), 20 \mathrm{PD}$ patients with mutations in

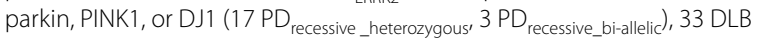
patients without $G B A$ mutation ( $\left(\mathrm{L}_{B s p o r a d i c}\right)$ and $16 \mathrm{DLB}$ patients with GBA mutation $\left(D L_{B G B A}\right)$ was available. Repeated lumbar punctures allowing longitudinal CSF measurements were performed in 100 PD patients (61 PDwildtype, $34 \mathrm{P}_{\mathrm{DGBA}}, 2 \mathrm{PD}_{\mathrm{LRRK} 2}, 3 \mathrm{PD}_{\text {recessive_heterozygous }}$ ).

Aditional file 3: Table S2. Intra-batch and inter-batch (overall) coefficients of variation (\%) of quantitative RT-QulC parameters Imax and AUC of the positive control, before (raw) and after normalization. The intrabatch coefficients of variation (CV) of the maximum intensity of fluorescence (I max) and area under the curve (AUC) are expressed as percentage of the ratio between standard deviation and average.

Additional file 4: Table S3. RT-QulC seeding profiles in DLB stratified by GBA mutation status. The table shows the a-syn seeding profiles of the analysed DLB group (number of positive replicates, area under the curve, Imax and LAG) together with the quantification of CSF A 1 1-42, t-Tau, $\mathrm{p}$-Tau and NFL (all measures are expressed in $\mathrm{pg} / \mathrm{ml}$ ).3.Additional file 3: Table S3 (.txt). RT-QulC seeding profiles in DLB stratified by GBA mutation status. The table shows the $a$-syn seeding profiles of the analysed DLB group (number of positive replicates, area under the curve, Imax and LAG) together with the quantification of CSF A 1-42, t-Tau, p-Tau and NFL (all measures are expressed in $\mathrm{pg} / \mathrm{ml}$ ).

Aditional file 5: Table S4. Correlations between CSF RT-QulC alphasynuclein seeding parameters with clinical measures and with CSF protein levels related to alpha-synuclein proteostasis in PD and DLB. RT-QulC alpha-synuclein seeding activity is associated with higher motor impairment as measured by the Unified Parkinson Disease Rating Scale III (UPDRS III) and lower cognitive function measured by Montreal Cognitive Assessment (MoCA). Moreover, higher RT-QulC alpha-synuclein seeding capacity is associated with lower CSF levels of proteins that are linked to lysosomal dysfunction and neurotransmitter secretion.

Additional file 6: Table S5. Clinical and CSF characteristics of RT-QulC seeders vs. non-seeders. p-Value significantly different between RT-QulC alpha-synuclein seeders vs. non-seeders in the respective diagnostic groups.

\section{Acknowledgements}

We wish to thank Dr. Byron Caughey (RML, NIAID, USA) for providing us with human wild-type a-Syn expressing plasmid.

\section{Authors' contributions}

Conception and design of the study: KB, SL, PP. Execution of the study: KB (clinical and lumbar puncture), CQ (RT-QulC execution and data analysis), IW (clinical and lumbar puncture), MR (recombinant a-syn production and quality control, RT-QulC execution), BR (clinical and lumbar puncture), SB (RT-QulC data analysis, figure preparation), MZ (clinical and lumbar puncture), AM (RTQulC execution), AKH (genetic analysis), CD, CS (genetic analysis), KW (hSYN ELISA), IL (hSYN ELISA), SS (mass spectrometry measurements of CSF proteins), $A B$ (mass spectrometry measurements of CSF proteins), KB (mass spectrometry measurements of CSF proteins), $\mathrm{HZ}$ (mass spectrometry measurements of CSF proteins), TG (clinical and lumbar puncture), PP. Statistical analysis: KB, PP. Manuscript preparation: KB, PP. Critical review of the manuscript: CQ, SL, IW, $M R, B R, S B, M Z, A M, A K H, C D, C S, K W, I L, S S, A B, K B, H Z$, TG. All authors read and approved the final manuscript.

\section{Funding}

Supported by the Italian Ministry of Health ("Ricerca Corrente"), the Carisbo Foundation, BMBF (PDdementia) and DZNE (PD research; MIGAP study). Moreover, it was funded by the PD-Strat project (FKZ 031L0137B) which was 
supported by the German Federal Ministry of Education and Research (BMBF) in the frame of ERACoSysMed2, and the Swedish Research Council (\#201802532), the European Research Council (\#681712), and Swedish State Support for Clinical Research (\#ALFGBG-720931). HZ is a Wallenberg Scholar.

\section{Availability of data and materials}

Anonymized data are available upon reasonable request to: kathrin.brockmann@uni-tuebingen.de.

\section{Declarations}

\section{Ethics approval and consent to participate}

The study was approved by the Ethics Committee of the University of Tuebingen (26/2007BO1, 404/2010BO1, 199/2011BO1, 702/2013BO1). All participants gave written informed consent.

\section{Consent for publication}

Not applicable.

\section{Competing interests}

$\mathrm{KW}$ is employed by Roboscreen $\mathrm{GmbH}$ and receive income from that Company, which manufactures the ELISA kit for measurements of total human a-Syn used in the present study. IL is employed by Roboscreen $\mathrm{GmbH}$ and receive income from that Company, which manufactures the ELISA kit for measurements of total human a-Syn used in the present study. KB is a co-founder of Brain Biomarker Solutions in Gothenburg AB (BBS), of which biomarkers were measured for the present study. $\mathrm{HZ}$ is a co-founder of Brain Biomarker Solutions in Gothenburg AB (BBS), of which biomarkers were measured for the present study. KB, CQ, SL, MR, IW, SB, BR, MZ, AM, AKH, CD, CS, AB, and $\mathrm{SS}, \mathrm{TG}$, and PP have nothing to report.

\section{Author details}

'Department of Neurodegeneration, Center of Neurology, Hertie Institute for Clinical Brain Research, German Center for Neurodegenerative Diseases, University of Tuebingen, Hoppe Seyler-Strasse 3, 72076 Tuebingen, Germany. ${ }^{2}$ German Center for Neurodegenerative Diseases, University of Tuebingen, Tuebingen, Germany. ${ }^{3}$ RCCS Istituto delle Scienze Neurologiche di Bologna, Via Altura 1/8, 40139 Bologna, Italy. ${ }^{4}$ Department of Experimental, Diagnostic and Specialty Medicine (DIMES), University of Bologna, Bologna, Italy. ${ }^{5}$ Roboscreen GmbH, Leipzig, Germany. ${ }^{6}$ Department of Psychiatry and Neurochemistry, Institute of Neuroscience and Physiology, The Sahlgrenska Academy at the University of Gothenburg, Mölndal, Sweden. ${ }^{7}$ Clinical Neurochemistry Laboratory, Sahlgrenska University Hospital, Mölndal, Sweden. ${ }^{8}$ Department of Neurodegenerative Disease, UCL Institute of Neurology, Queen Square, London, UK. ${ }^{9}$ UK Dementia Research Institute at UCL, London, UK.

\section{Received: 14 September 2021 Accepted: 13 October 2021}

Published online: 30 October 2021

\section{References}

1. Dickson DW, Braak H, Duda JE, Duyckaerts C, Gasser T, Halliday GM et al (2009) Neuropathological assessment of Parkinson's disease: refining the diagnostic criteria. Lancet Neurol 8:1150-1157. https://doi.org/10.1016/ S1474-4422(09)70238-8

2. Goedert M, Masuda-Suzukake M, Falcon B (2017) Like prions: the propagation of aggregated tau and alpha-synuclein in neurodegeneration. Brain J Neurol 140:266-278. https://doi.org/10.1093/brain/aww230

3. Spillantini MG, Schmidt ML, Lee VM, Trojanowski JQ, Jakes R, Goedert M (1997) Alpha-synuclein in Lewy bodies. Nature 388:839-840. https://doi. org $/ 10.1038 / 42166$

4. Schneider SA, Alcalay RN (2017) Neuropathology of genetic synucleinopathies with parkinsonism: review of the literature. Mov Disord 32:1504-1523. https://doi.org/10.1002/mds.27193

5. Heckman MG, Soto-Ortolaza Al, Contreras MYS, Murray ME, Pedraza O, Diehl NN et al (2016) LRRK2 variation and dementia with Lewy bodies.
Parkinsonism Relat Disord 31:98-103. https://doi.org/10.1016/j.parkreldis. 2016.07.015

6. Kalia LV, Lang AE, Hazrati LN, Fujioka S, Wszolek ZK, Dickson DW et al (2015) Clinical correlations with Lewy body pathology in LRRK2-related Parkinson disease. JAMA Neurol 72:100-105. https://doi.org/10.1001/ jamaneurol.2014.2704

7. Zimprich A, Biskup S, Leitner P, Lichtner P, Farrer M, Lincoln S et al (2004) Mutations in LRRK2 cause autosomal-dominant parkinsonism with pleomorphic pathology. Neuron 44:601-607. https://doi.org/10.1016/j. neuron.2004.11.005

8. Lerche S, Wurster I, Roeben B, Zimmermann M, Riebenbauer B, Deuschle C et al (2020) Parkinson's disease: glucocerebrosidase 1 mutation severity is associated with CSF alpha-synuclein profiles. Mov Disord 35:495-499. https://doi.org/10.1002/mds.27884

9. Malek N, Swallow D, Grosset KA, Anichtchik O, Spillantini M, Grosset DG (2014) Alpha-synuclein in peripheral tissues and body fluids as a biomarker for Parkinson's disease — a systematic review. Acta Neurol Scand 130:59-72. https://doi.org/10.1111/ane.12247

10. Mollenhauer B, Caspell-Garcia CJ, Coffey CS, Taylor P, Singleton A, Shaw LM et al (2019) Longitudinal analyses of cerebrospinal fluid alpha-Synuclein in prodromal and early Parkinson's disease. Mov disord 34:13541364. https://doi.org/10.1002/mds.27806

11. Fairfoul G, McGuire LI, Pal S, Ironside JW, Neumann J, Christie S et al (2016) Alpha-synuclein RT-QulC in the CSF of patients with alpha-synucleinopathies. Ann Clin Transl Neurol 3:812-818. https://doi.org/10.1002/acn3.338

12. Shahnawaz M, Tokuda T, Waragai M, Mendez N, Ishii R, Trenkwalder C et al (2017) Development of a biochemical diagnosis of Parkinson disease by detection of alpha-synuclein misfolded aggregates in cerebrospinal fluid. JAMA Neurol 74:163-172. https://doi.org/10.1001/jamaneurol.2016.4547

13. Kang UJ, Boehme AK, Fairfoul G, Shahnawaz M, Ma TC, Hutten SJ et al (2019) Comparative study of cerebrospinal fluid alpha-synuclein seeding aggregation assays for diagnosis of Parkinson's disease. Mov disord 34:536-544. https://doi.org/10.1002/mds.27646

14. Rossi M, Candelise N, Baiardi S, Capellari S, Giannini G, Orru CD et al (2020) Ultrasensitive RT-QulC assay with high sensitivity and specificity for Lewy body-associated synucleinopathies. Acta Neuropathol 140:49-62. https:// doi.org/10.1007/s00401-020-02160-8

15. Garrido A, Fairfoul G, Tolosa ES, Marti MJ, Green A, Barcelona LSG (2019) alpha-synuclein RT-QulC in cerebrospinal fluid of LRRK2-linked Parkinson's disease. Ann Clin Transl Neurol 6:1024-1032. https://doi.org/10. 1002/acn3.772

16. Jankovic J, Tan EK (2020) Parkinson's disease: etiopathogenesis and treatment. J Neurol Neurosurg Psychiatry 91:795-808. https://doi.org/10. 1136/jnnp-2019-322338

17. Lerche S, Wurster I, Roben B, Zimmermann M, Machetanz G, Wiethoff S et al (2020) CSF NFL in a longitudinally assessed PD cohort: age effects and cognitive trajectories. Mov disord 35:1 138-1144. https://doi.org/10. $1002 / m d s .28056$

18. Litvan I, Bhatia KP, Burn DJ, Goetz CG, Lang AE, McKeith I et al (2003) Movement Disorders Society Scientific Issues Committee report: SIC Task Force appraisal of clinical diagnostic criteria for Parkinsonian disorders. Mov disord 18:467-486. https://doi.org/10.1002/mds.10459

19. McKeith IG, Boeve BF, Dickson DW, Halliday G, Taylor JP, Weintraub D et al (2017) Diagnosis and management of dementia with Lewy bodies: fourth consensus report of the DLB Consortium. Neurology 89(1):88-100. https://doi.org/10.1212/WNL.00000000000004058

20. Goetz CG, Tilley BC, Shaftman SR, Stebbins GT, Fahn S, Martinez-Martin P et al (2008) Movement disorder society-sponsored revision of the unified Parkinson's disease rating scale (MDS-UPDRS): scale presentation and clinimetric testing results. Mov disord 23:2129-2170. https://doi.org/10. $1002 /$ mds. 22340

21. Goetz CG, Poewe W, Rascol O, Sampaio C, Stebbins GT, Counsell C et al (2004) Movement disorder society task force report on the Hoehn and Yahr staging scale: status and recommendations. Mov disord 19:10201028. https://doi.org/10.1002/mds.20213

22. Hoops S, Nazem S, Siderowf AD, Duda JE, Xie SX, Stern MB et al (2009) Validity of the MoCA and MMSE in the detection of MCl and dementia in Parkinson disease. Neurology 73:1738-1745. https://doi.org/10.1212/ WNL.0b013e3181c34b47 
23. Folstein MF, Folstein SE, McHugh PR (1975) "Mini-mental state". A practical method for grading the cognitive state of patients for the clinician. J Psychiatr Res 12:189-198. https://doi.org/10.1016/0022-3956(75)90026-6

24. Bergeron D, Flynn K, Verret L, Poulin S, Bouchard RW, Bocti C et al (2017) Multicenter validation of an MMSE-MoCA conversion table. J Am Geriatr Soc 65:1067-1072. https://doi.org/10.1111/jgs.14779

25. Rossi M, Baiardi S, Teunissen CE, Quadalti C, vandeBeek M, Mammana A, et al (2021) Diagnostic value of the CSF alpha-synuclein real-time quaking-induced conversion assay at the prodromal $\mathrm{MCl}$ stage of dementia with Lewy bodies. Neurology. https://doi.org/10.1212/WNL.0000000000 012438

26. Brinkmalm G, Sjodin S, Simonsen AH, Hasselbalch SG, Zetterberg H, Brinkmalm A et al (2018) A parallel reaction monitoring mass spectrometric method for analysis of potential CSF biomarkers for Alzheimer's disease. Proteom Clin Appl. https://doi.org/10.1002/prca.201700131

27. Sjödin S, Brinkmalm G, Öhrfelt A, Parnetti L, Paciotti S, Hansson O et al (2019) Endo-lysosomal proteins and ubiquitin CSF concentrations in Alzheimer's and Parkinson's disease. Alzheimers Res Ther 11:82. https:// doi.org/10.1186/s13195-019-0533-9

28. Iranzo A, Fairfoul G, Ayudhaya ACN, Serradell M, Gelpi E, Vilaseca I et al (2021) Detection of a-synuclein in CSF by RT-QulC in patients with isolated rapid-eye-movement sleep behaviour disorder: a longitudinal observational study. Lancet Neurol 20(3):203-212. https://doi.org/10. 1016/S1474-4422(20)30449-X

29. Poulopoulos M, Levy OA, Alcalay RN (2012) The neuropathology of genetic Parkinson's disease. Mov disord 27:831-842. https://doi.org/10. 1002/mds.24962

30. Rotunno MS, Lane M, Zhang W, Wolf P, Oliva P, Viel C et al (2020) Cerebrospinal fluid proteomics implicates the granin family in Parkinson's disease. Sci Rep 10:2479. https://doi.org/10.1038/s41598-020-59414-4

31. van Steenoven I, Koel-Simmelink MJA, Vergouw LJM, Tijms BM, Piersma SR, Pham TV et al (2020) Identification of novel cerebrospinal fluid biomarker candidates for dementia with Lewy bodies: a proteomic approach. Mol Neurodegener 15:36. https://doi.org/10.1186/ s13024-020-00388-2
32. Boiten WA, van Steenoven I, Xiao M, Worley PF, Lemstra AW, Teunissen CE (2020) Pathologically decreased CSF levels of synaptic marker NPTX2 in DLB are correlated with levels of alpha-synuclein and VGF. Cells. https:// doi.org/10.3390/cells10010038

33. van Steenoven I, Noli B, Cocco C, Ferri GL, Oeckl P, Otto M et al (2019) VGF Peptides in Cerebrospinal Fluid Of Patients With Dementia With Lewy bodies. Int J Mol Sci. https://doi.org/10.3390/ijms20194674

34. Gegg ME, Burke D, Heales SJ, Cooper JM, Hardy J, Wood NW et al (2012) Glucocerebrosidase deficiency in substantia nigra of parkinson disease brains. Ann Neurol 72:455-463. https://doi.org/10.1002/ana.23614

35. Hasegawa M, Fujiwara H, Nonaka T, Wakabayashi K, Takahashi H, Lee VM et al (2002) Phosphorylated alpha-synuclein is ubiquitinated in alphasynucleinopathy lesions. J Biol Chem 277:49071-49076. https://doi.org/ 10.1074/jbc.M208046200

36. Kuzuhara S, Mori H, Izumiyama N, Yoshimura M, Ihara Y (1988) Lewy bodies are ubiquitinated. A light and electron microscopic immunocytochemical study. Acta Neuropathol 75:345-353. https://doi.org/10.1007/ BF00687787

37. Moors TE, Paciotti S, Ingrassia A, Quadri M, Breedveld G, Tasegian A et al (2019) Characterization of brain lysosomal activities in GBA-related and sporadic Parkinson's disease and dementia with Lewy bodies. Mol neurobiol 56:1344-1355. https://doi.org/10.1007/s12035-018-1090-0

38. Murphy KE, Gysbers AM, Abbott SK, Tayebi N, Kim WS, Sidransky E et al (2014) Reduced glucocerebrosidase is associated with increased alphasynuclein in sporadic Parkinson's disease. Brain J Neurol 137:834-848. https://doi.org/10.1093/brain/awt367

39. Schondorf DC, Aureli M, McAllister FE, Hindley CJ, Mayer F, Schmid B et al (2014) iPSC-derived neurons from GBA1-associated Parkinson's disease patients show autophagic defects and impaired calcium homeostasis. Nat Commun 5:4028. https://doi.org/10.1038/ncomms5028

\section{Publisher's Note}

Springer Nature remains neutral with regard to jurisdictional claims in published maps and institutional affiliations.
Ready to submit your research? Choose BMC and benefit from:

- fast, convenient online submission

- thorough peer review by experienced researchers in your field

- rapid publication on acceptance

- support for research data, including large and complex data types

- gold Open Access which fosters wider collaboration and increased citations

- maximum visibility for your research: over $100 \mathrm{M}$ website views per year

At BMC, research is always in progress.

Learn more biomedcentral.com/submissions 